MANUAL FOR NURSES IN HOSPITALS FOR MENTAL DISEASES, BY DR. JULES MOREL.

In regard to the footnote to the review of this manual in our last issue we are requested by Dr. Morel to state that the Superioress of the Sisters of Charity paid the printing expenses of copies of his manual for the Sisters engaged in nursing the insane in their asylums.

\title{
CARE AND TREATMENT OF THE INSANE.
}

The Third International Congress for the Care and Treatment of the Insane will be held at Vienna from the 7 th to the IIth October, 1908.

The Council of the Medico-Psychological Association have been asked to nominate a Committee to represent the Association. It will facilitate the formation of such if members, intending to be present or willing to read or send a paper, will kindly at once notify the General Secretary of their intention.

\section{THE SIXTEENTH INTERNATIONAL MEDICAL CONGRESS.}

This Congress will be held at Budapest from the 29th August to the 4th September, 1909. The General Secretary is Professor Emil Grósz, M.D., Budapest, viii, Esterházyutcza 7.

\section{NOTICES OF MEETINGS.}

\section{Medico-Psychological Association.}

The sixty-seventh Annual Meeting of the Association will be held on Thursday and Friday, 23rd and 24th July, 1908, at the rooms of the Association, 11, Chandos Street, Cavendish Square, London, W., under the Presidency of Dr. Charles Mercier. There will be meetings of Committees as follows:-On Wednesday, 22nd July, Criminal Procedure Committee at 2 p.m., Parliamentary Committee at 3 p.m., Educational Committee at 4 p.m. The Council will meet at 9.30 a.m. on Thursday, 23rd July.

The Annual Meeting will commence at 11 a.m. on Thursday, 23rd July, when the usual business of the Association will be transacted.

Notice of motion by Dr. D. G. Thомson: That for the more efficient teaching and training of the coming generation of Alienists in Psychiatry, the MedicoPsychological Association-in the first instance, through its Education Committee-consider some scheme for post-graduate teaching and training, with or without the imprimatur of a diploma given after such a course (with or without examination) with a view to its being brought before the Universities and other qualifying and teaching bodies.

(Dr. Thomson's paper leading up to this motion, which was read at the last Quarterly Meeting, appears in this number, see page 550).

2 p.m. - The President's Address, after which the adjourned discussion will take place on "Boarding-out of the Insane in Private Dwellings," on which a paper, with lantern illustrations, was given by R. Cunyngham Brown, M.D., at the meeting held last February (see page 532).

Friday, 24th July, at II a.m.-RobrRT JONES, M.D., F.R.C.P.(Lond.), F.R.C.S., will initiate a discussion on "The Case against Dementia Præcox." LEw is C. BRUCE, M.D., F.R.C.P.(Edin.), will introduce a discussion on "Folie Circulaire and Manic-depressive Insanity-their identity ?, and the Relation of the Depressed to the Elevated Stage." Alan McDougall, M.D.(Vict.), will read a paper "On the Principles of the Treatment of Epilepsy."

LIV. 